\title{
Perfil de la revista Ingeniería y Competitividad: Modelos de medición y estadísticas
}

\section{Ingeniería y Competitividad Journal profile: Measurement models and statistics}

\author{
Alba Lucia Cifuentes-González ${ }^{1}$, Fiderman Machuca-Martínez ${ }^{1}$ (id \\ ${ }^{1}$ Universidad del Valle, Facultad de Ingeniería, Cali, Colombia \\ alba.cifuentes@correounivalle.edu.co, fiderman.machuca@correounivalle.edu.co
}

La revista Ingeniería y Competitividad de la facultad de ingeniería de la Universidad del Valle inicio su publicación en el año 1997 con seis artículos, los cuales están disponibles en su página

web (https://revistaingenieria.univalle.edu.co/index.p hp/ingenieria_y_competitividad/issue/view/259).

A lo largo de su historia, la revista ha crecido en importancia y ha recorrido diferentes etapas de acuerdo a los modelos de medición establecidos por Publindex, así: 2005 a 2007 Categoría C; 2008 Categoría B; 2009 a 2018 Categoría A2; 2019 a 2020 Categoría C y 2021 Categoría B.

El cambio de categoría implica retos pues el número de solicitudes de artículos se incrementa o disminuye de manera critica, lo que se traduce en dificultades en la edición de los números de la revista. La Figura 1 muestra la distribución de artículos publicados desde el 2012. Se puede observar que durante los periodos de categorías superior el volumen de publicaciones es mas alto, a partir del 2018 se ha mantenido estable el número de artículos, se prevé un aumento sustancial para el 2021.
La indexación de la revista en las diferentes bases de datos ha sido crucial para su crecimiento y difusión y consulta. En particular el ingreso a Scielo y a través de esta a WoS (Emerging Sources Citation Index) hacen que la revista tome un entorno global y esta sea atractiva para autores de los países donde la revista sea reconocida y avalada por las autoridades de los sistemas de ciencia y tecnología.

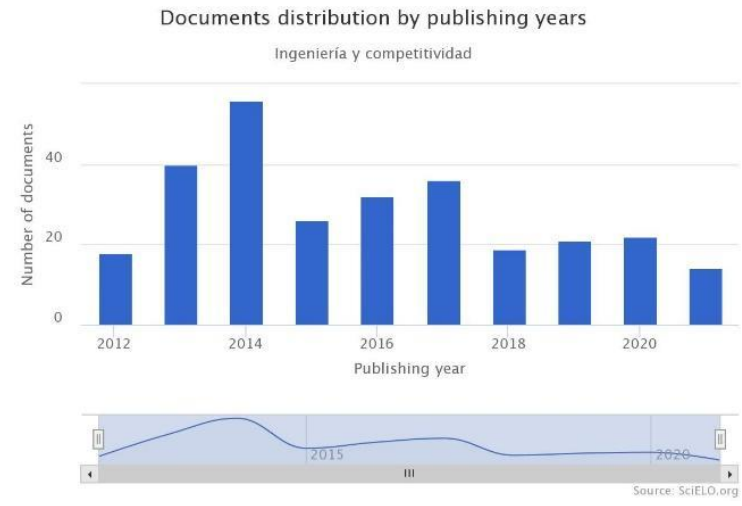

Figura 1. Distribución de documentos publicados por la revista ingeniería y competitividad

A partir de los datos de WoS, la revista presenta el siguiente perfil (28-04-2021) de los artículos publicados en el periodo 1980 a 2021: 357 publicaciones; $\mathrm{h}=7$; Promedio de citas por 
elemento 0,87; Total de veces citado 309; sin citas propias 296; Artículos en que se cita 304; sin citas propias 292.

Es interesante ver las estadísticas de las citaciones externas (292) y el perfil de estas para tener una impresión del impacto de la revista y su evolución en el contexto colombiano. La Figura 2 muestra como se ha incrementado las citas de los artículos a partir del año 2017 (44) al 2020 (79), en contraste a los años 2015 (6) y 2014 (2).

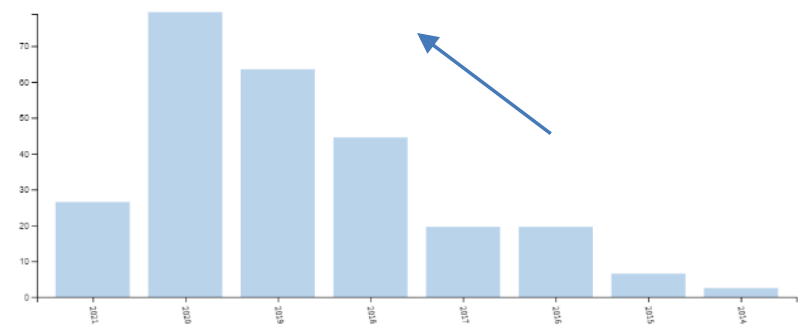

Figura 2. Citaciones recibidas por la revista Ingeniería y Competitividad 2014-2021

Por otra parte, es interesante conocer las áreas de investigación, las revistas y los países que están citando los artículos de la revista. Las Figuras 3, 4 y 5 muestran estos perfiles.

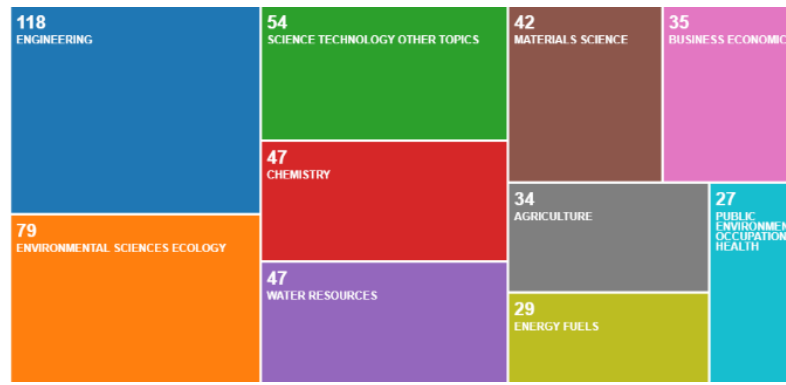

Figura 3. Perfil de áreas de investigación de las citas recibidas por la revista Ingeniería y Competitividad

Otra estadística interesante, es el número de autores de los documentos publicados y su relación con los incentivos que reciben los autores del artículo en las instituciones (Figura 6). Al parecer el número de tres autores guarda relación con los incentivos del decreto 1279 (para universidades públicas) donde establece este número como máximo en el reconocimiento de incentivos pues a mayor número de autores el incentivo disminuye.

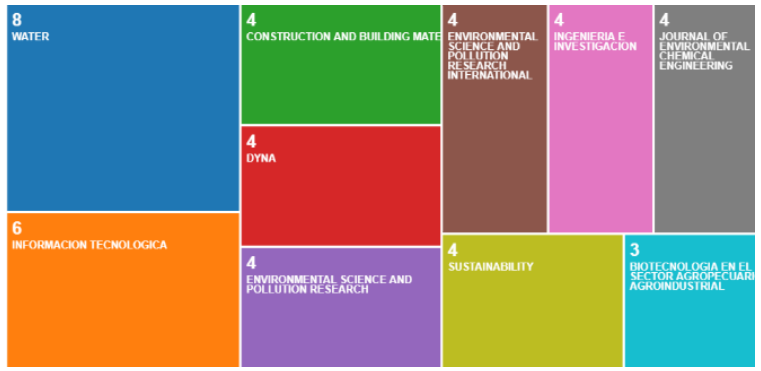

Figura 4. Revistas que citan los artículos de la revista Ingeniería y Competitividad

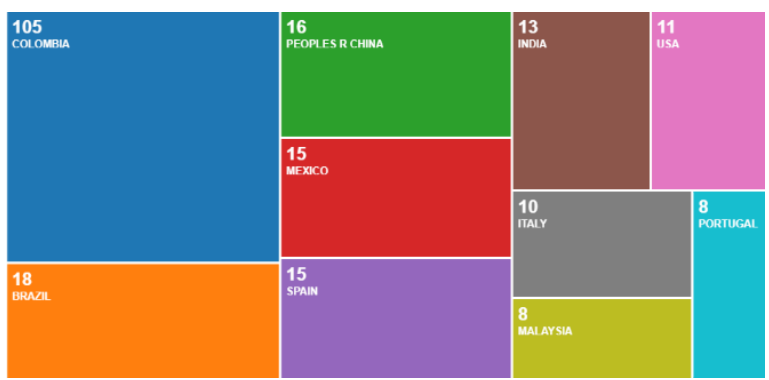

Figura 5. Países que citan la revista Ingeniería y Competitividad

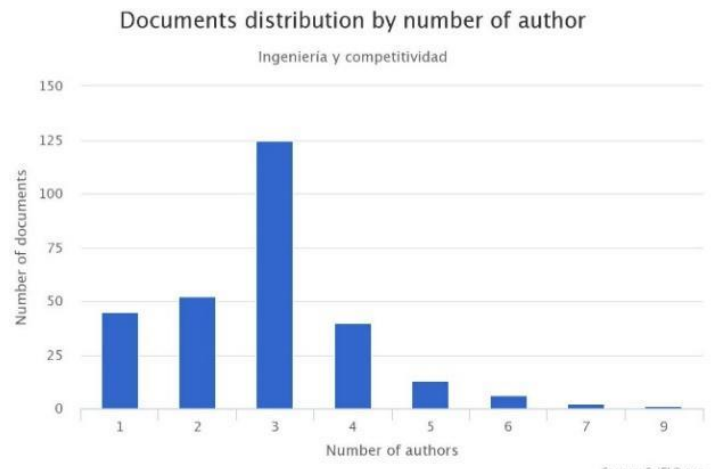

Figura 6. Número de autores por artículo en la revista Ingeniería y Competitividad

Para la comunidad universitaria de la Universidad del Valle y del país, la revista de la Facultad de Ingeniería ha sido y será un elemento de difusión de la actividad docente y de investigación en los diferentes campos del saber para beneficio de la sociedad 